\title{
Analysing lecturers' perceptions on traditional vs. distance learning: A conceptual study of emergency transferring to distance learning during COVID-19 pandemic
}

\author{
Mohd Khaled Yousef Shambour ${ }^{1}$. Muhannad A. Abu-Hashem ${ }^{2}$
}

Received: 6 April 2021 / Accepted: 16 August 2021 / Published online: 16 September 2021 (c) The Author(s), under exclusive licence to Springer Science+Business Media, LLC, part of Springer Nature 2021

\begin{abstract}
In recent years, and also due to the COVID-19 pandemic, education institutions worldwide have changed their education paradigm from a traditional to an online system. These institutions have rapidly accomplished their educational programs and activities by supporting various web applications, allowing the completion of the education process remotely. This motivated us to investigate the general perceptions of the faculty members who are teaching different courses for undergraduate students using the distance education system. The proposed technique is based on the use of advanced analysis methods to test the hypothesis of instructors' perceptions of online teaching effectiveness, compared with traditional teaching, will not be affected by the following eight factors, including gender, academic major, age, academic degree, country of teaching, teaching experience in traditional classes, teaching experience in virtual classes (VCs), and whether or not the department/ faculty provided e-learning courses before the COVID-19 pandemic. A total of 187 lecturers from 71 departments in 24 educational institutions located in 11 countries participated in this research. Results indicate that the perceptions of instructors regarding the online teaching system generally do not change based on the studied factors. Furthermore, the quantitative analyses illustrate that no significant differences exist in all dimension scales in terms of gender, major specification, age, country of teaching, and virtual experience. Significant differences are found in the dimension scale of distance education effectiveness in terms of academic degree and the educator status in terms of supporting VCs and traditional experience dimension scales. Additionally, the study provides various recommendations, including that the departments should encourage instructors to positively adapt with online teaching by developing the required skills and knowledge. Moreover, departments and institutions should support the teaching staff with specialized education tools. In addition, instructors should strive to decrease the communication and interaction gap between distance education and traditional in-class teaching.
\end{abstract}

Extended author information available on the last page of the article 
Keywords COVID-19 - Education institution · Data analysis · Web applications ·

Teachers' perceptions $\cdot$ Online courses

\section{Introduction}

Distance learning has been used before the emergence of personal computers and the Internet, but the spread of personal computers and the availability of the Internet have contributed significantly to the wide reach of distance learning Uhlig (2002). Online learning has rapidly grown, especially in the last decade Willett et al. (2019). This growth entails the merging of online learning into educational systems as part of the formal educational process Al-Shboul (2013) and Nelson (2003).

Recently, a new type of coronavirus, called COVID-19, surfaced in China, and initial reports of its spread began in mid-December 2019 in Wuhan City [1]. Since then, cases of COVID-19 infections have increased rapidly worldwide, causing massive death rates. Consequently, this has led to the implementation of strict measures by national governments to prevent its spread, including the isolation of cities, travel restrictions from one city to another, and the closure of airports, malls, restaurants, shops, and educational facilities. The pandemic has also significantly affected many research projects and studies Shambour and Gutub (2021). Nevertheless, education programs have continued in many countries without the need for physical meetings between lecturers and students through the provision of courses via remote platforms and virtual learning environments, such as Blackboard [2], Moodle [3], Webex [4], Canvas [5], and so on. The main challenge facing educators today is primarily how to effectively manage and deliver educational services and curricula to stakeholders, the education community, and the marketplace Okoye et al. (2021). Some educational institutions have faced many challenges in transferring the entire learning process from traditional to virtual classrooms, especially those who have no experience in providing online courses. However, online courses must maintain and enhance the teaching quality to ensure the educational performance of students Hsiao (2021).

Fundamentally, 187 university lecturers of various disciplines and teaching experiences participated in the current study. The perceptions of lecturers who used the traditional and online systems during their teaching processes were examined and analyzed on the basis of three scales: distance education effectiveness, distance education compared to traditional education, and educator status. This study mainly aims to explore the influences of several factors on teachers' perspectives and explore the differences in lecturers' views toward teaching courses in traditional and online systems.

The paper is organized as follows. Section 2 provides some related works for the traditional and online teaching paradigms. Section 3 presents the methodology. Section 4 discusses the data analysis and results. Finally, Sect. 5 concludes the paper and provides recommendations for future work. 


\section{Related literature}

Several studies have discussed the effects of learning effectiveness in traditional and virtual classrooms. Some of them pointed out the benefits of effective learning through traditional classrooms (Arias et al., 2018;), some have praised the effectiveness of virtual classroom teaching (Liu, 2010; Narayan \& Singh, 2020; Trakru \& Jha, 2019), and others have recommended the use of a hybrid approach (Khatri et al., 2013). Lecturers play a crucial role in the learning process and they strive to deliver the knowledge to students, especially in remote teaching. Thus, teachers' perceptions about distance education must be studied and identified to provide recommendations for the development and improvement of the quality of the educational process.

Furthermore many studies in literature have measured lecturers' preferences and performances in online and traditional face-to-face learning systems, including Shachar and Neumann (2003), Bernard et al. (2004), Allen et al. (2002), Sitzmann et al. (2006), Hurlbut (2018), Yerby and Floyd (2013), Hannay and Newvine (2006), and Sibirskaya et al. (2019). Other studies discussed the advantages and disadvantages of using both systems, such as in Behzadi and Ghaffari (2011), Gowda and Suma (2017), and Lazou and Tsinakos (2019).

Saleh and Mrayan (2016) examined the Arab Open University in Jordan as a case study on faculty perceptions of online education programs. They examined the faculty's perceived values of online learning effectiveness, the interaction between the teacher and student, the adequacy of the provided technology by the institute, the teaching techniques used, and the performances of students. They reported that the faculty members are generally satisfied with online education despite that they favored face-to-face and blended courses in teacher training programs.

To improve the distance education system, Gürer et al. (2016) examined the opinions of instructors who have experienced online teaching. They interviewed 12 instructors to produce some suggestions that can contribute to online learning enhancement. The study presents the positive and negative sides of online learning from the perspectives of the interviewed instructors. Meanwhile, Shreaves (2019) conducted a study on faculty perceptions of online teaching at the Pacific Lutheran University to highlight the factors that encourage and discourage online education application. The main goal of the study is to encourage and motivate the employment of online learning in Pacific Lutheran University. To provide a theoretical lens to examine the influence of attitudes, subjective norms, and perceived behavioral control, the decomposed theory of planned behavior (DTPB) is applied, and 50\% of the respondents highlighted 17 factors that influence the decision on whether or not to teach online.

Samuel (2016) conducted a study on the "presence" or the false impression of being in an actual classroom within an online learning environment. The goal of that study was to investigate and examine how the faculties who applied online courses perceive and experience presence. In addition, many studies targeted instructors' perceptions of best practices and quality outcomes Frazer et al. (2017), Plante and Asselin (2014), and Richardson et al. (2016). Frazer et al. (2017), for example, 
conducted a study on faculty perceptions of online teaching of nursing online education. The goal of their study was to characterize and express teaching effectiveness and quality indicators in an online environment, which did not require instructors and students to be online simultaneously. Eleven instructors were interviewed to achieve that goal. The study concluded by suggesting some useful practices that can support online education.

Meanwhile, a study that measured faculty members' perceptual differences in terms of distance education was conducted by Ulmer et al. (2007). However, it did not consider actual learning outcomes and the quality of distance education as part of the measurement. The findings of the study indicated that some degree of distance education effectiveness might be helpful if it is considered by higher education culture. A literature exploration during the time period of 1995-2015 was conducted by Wingo et al. (2017) to investigate faculty perceptions related to online teaching. They analyzed 67 studies to achieve that goal. The investigation revealed issues encountered by the faculty encounters in online teaching, such as student success, required technical support, work load, and others. McKenzie (2019) conducted a phenomenological study, which investigated instructor/student interaction during online courses and discussed various types of interactions along with some interaction obstacles. That study provided instructors and program administrators with useful and detailed descriptions of state-of-the art techniques of instructor/student online interaction.

Previous studies have analyzed and discussed lecturers' perception of online teaching and the effectiveness of online teaching in departments that used to support online teaching. In this study we aim to analyze and discuss lecturers' perception of online teaching in terms of emergence transfer from traditional in-class teaching to online teaching caused by the COVID-19 pandemic. Moreover, study analyzed the effectiveness of sudden transfer from traditional in-class teaching to online teaching during the COVID-19 pandemic.

\section{Methodology}

The section presents the methodology used in this paper, starting from reviewing the literature, defining research hypothesis, defining the research instrument, data analysis and discussion, and reporting of the results as shown in Fig. 1:

- Reviewing the Literature

A descriptive literature review was conducted in which the related works, main goal, methods, and results were generally discussed briefly as in the previous section. The main focus of the literature review was directed toward studies that targeted the experience of faculty members related to distance education programmers.

- Defining research hypothesis

An ANOVA statistical method, at alpha level of 0.05 , is used to observe whether a significant difference exists between the results collected from lec- 
Fig. 1 Research methodology

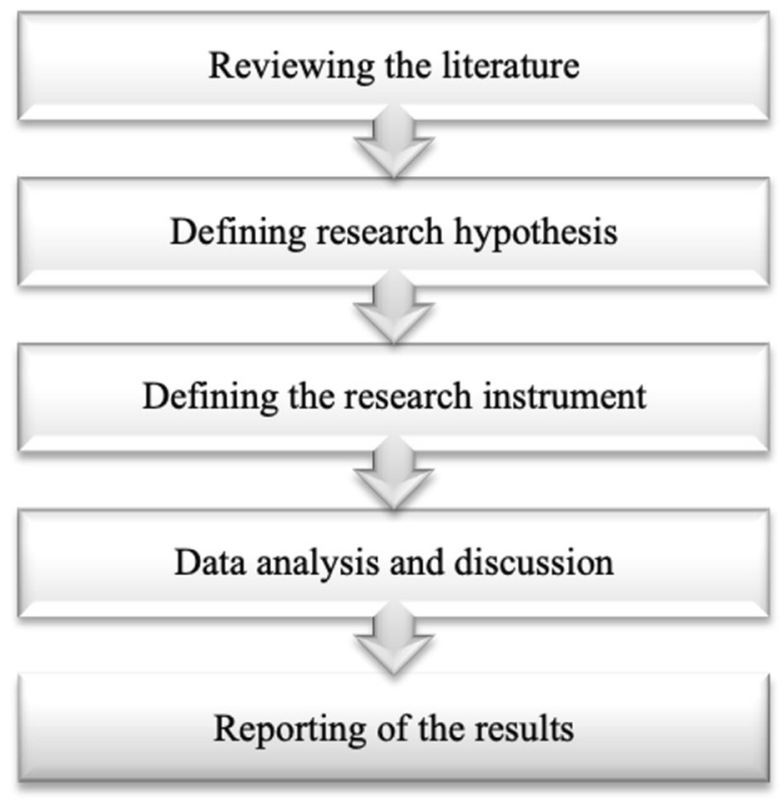

turers' perspectives of online teaching effectiveness compared with traditional teaching such that:

- The null hypothesis (H1) states that instructors' perception will not be affected by the factors of major, academic degree, country of teaching, age, teaching experience in traditional classes, teaching experience in virtual classes (VCs) and whether or not the department/faculty provided e-learning courses before the COVID-19 pandemic;

- The alternative hypothesis (H2) rejects the null one.

- Defining the research instrument

To study the lecturers' point of view on distance learning effectiveness during COVID-19, a research instrument (questionnaire) adopted from Ulmer et al. (2007) was used to obtain lectures' experiences and observations. The questionnaire comprises three scales, namely, distance education effectiveness, distance education compared to traditional education, and educator status. Each scale has a number of questions, as shown in Table 1. The questionnaire was developed using a Likert-type scale with five-point responses ranging from $1=$ strongly disagree to $5=$ strongly agree.

- Data analysis and discussion

Similar to the data analysis performed by Okoye et al. (2021), this study applied statistical inference-basis of theoretical distributions to analyze the collected data and explore the descriptive features using ANOVA statistical method 


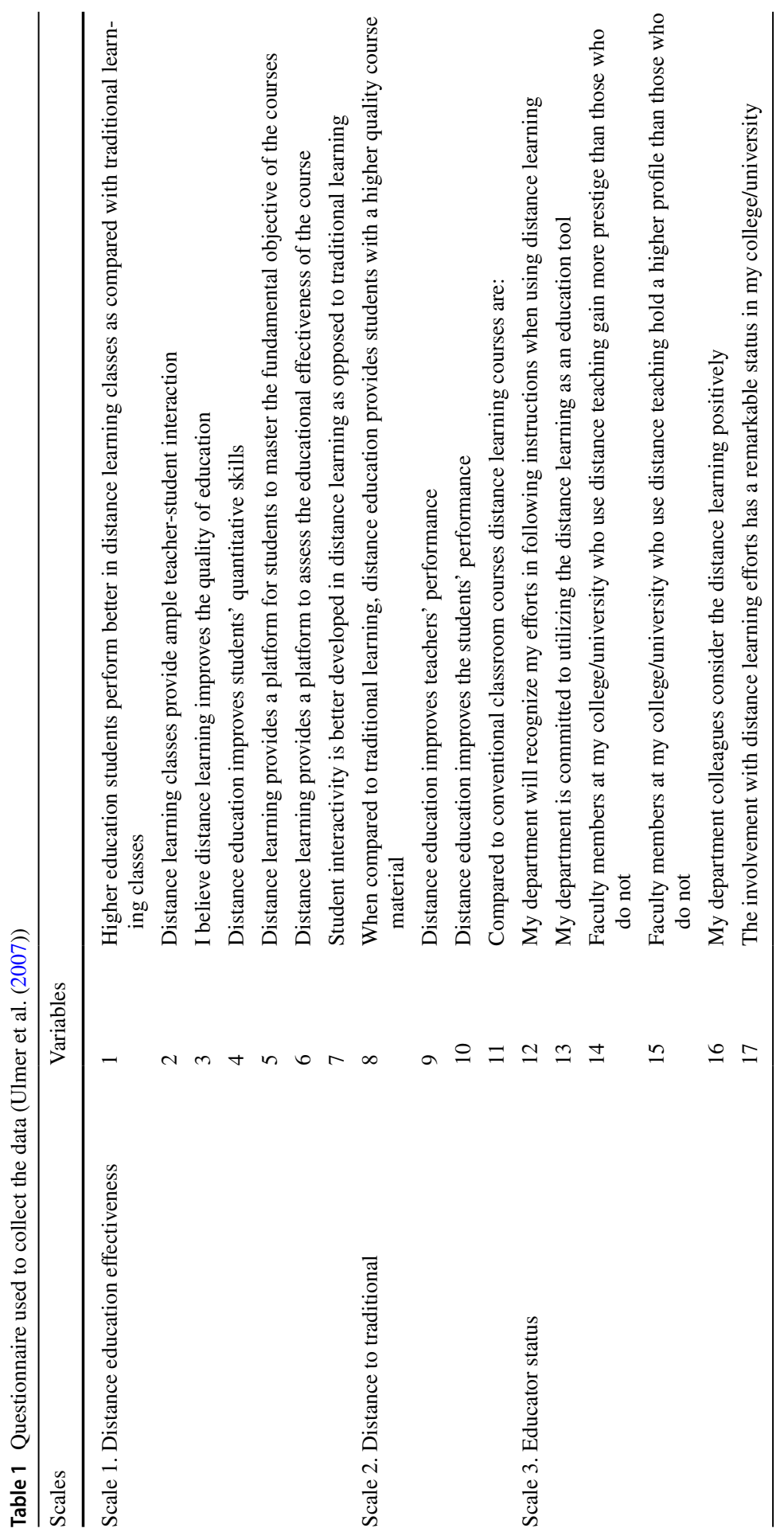


that reveals the factors that cause differences in the mean between different groups and determines whether statistically significant differences exist between groups. These were then used to test the hypothesis to realize the relationships among different variables and explore the teaching effectiveness on the basis of instructors' perceptions on practice teaching within the traditional and virtual online systems.

- Reporting of the results

This is the final step wherein the results of the analyzed data are discussed and presented so that the findings can provide valuable insights to researchers with varying interests and expertise. The authors declare that they had obtained an ethical approval from the Department of Information and Scientific Services at the Custodian of the Two Holy Mosques Institute for Hajj and Umrah Research, Umm Al-Qura University, Saudi Arabia.

\section{Data analysis and results}

\subsection{Demographic data}

The sample data were collected toward the end of the fall semester (May 27-31, 2020). A total of 187 lecturers were randomly selected to participate in this study, in which $70.9 \%$ were males and $29.1 \%$ were females, from 71 departments belonging to 24 educational institutions located in 11 countries.

The collected sample data were categorized to eight major factors: gender, participation based on general specialization, academic degree, country of teaching, age, teaching experience in traditional classes, teaching experience in VCs, and whether or not the department/faculty provided e-learning courses before the COVID-19 pandemic. The main idea behind these categorizations was to target the differences in opinions on the basis of different aspects.

Figure 2 shows the number of survey respondents in terms of general specialization. It also shows the percentage of participants in each category. Similar to a study conducted by Affouneh and Raba (2018), this study focuses several general specializations, including computer science and information technology (IT), medical/health sciences, social and human sciences, applied sciences, engineering sciences, and Sharia sciences. The majority of responses came from computer science and IT with $26 \%$ and medical/health sciences with $25 \%$ of the responses, respectively, which are in line with the results of Affouneh and Raba (2018).

Figure 3 provides the percentages of participants in terms of academic degree. Similar results were found in a study by Alshalawi (2019), which found that the majority of participants were associate professors (37\%), followed by associate professors and lecturers (22\% each). Moreover, the percentages of participants in terms of country of teaching are given in Fig. 4, where the responses came from Jordan (48.1\%), Saudi Arabia (31\%), Palestine (10.7\%), Egypt (3.2\%), Oman (1.6\%), 


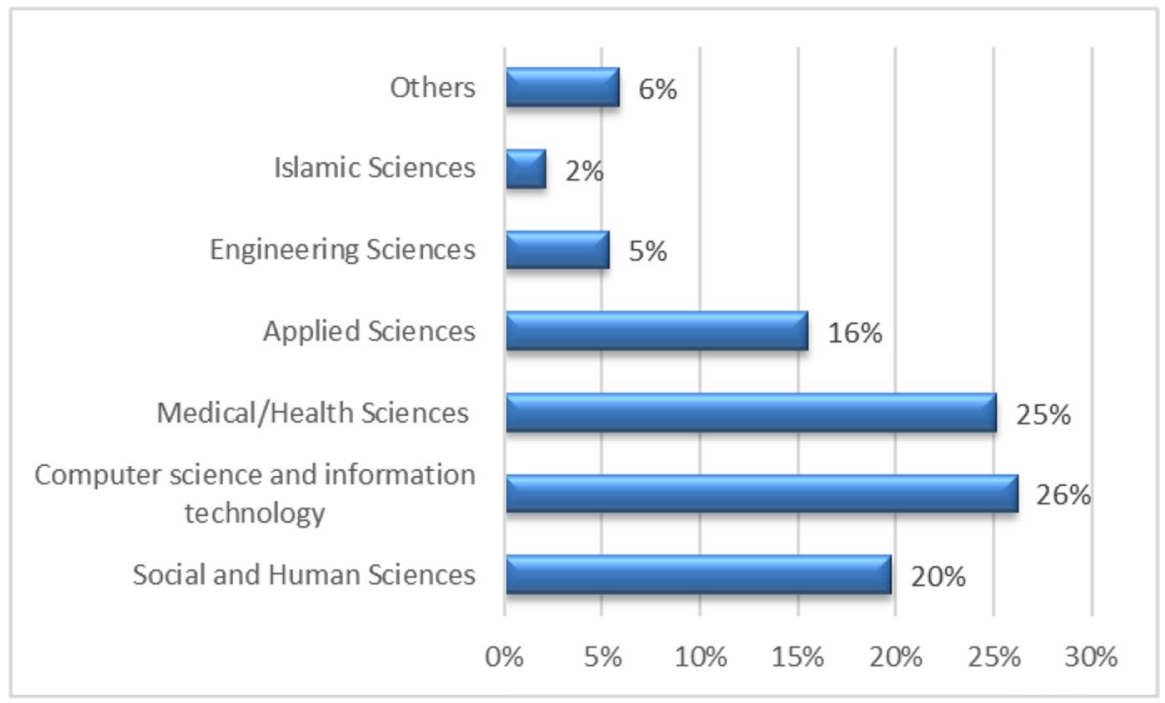

Fig. 2 Distribution of participants based on general specialization

Malaysia (1.6\%), and others-Tunisia, United Arab Emirates, Australia, United Kingdom, and - Sudan(3.7\%). Figure 5 shows the percentages of participants' ages. The majority of participants were between 30-40 (32.6\%) and 41-50 years $(29.9 \%)$.

A comparison between participants' teaching experience in traditional and VCs is shown in Fig. 6. The figure reveals that the majority of participants have higher experience in traditional classes compared with their experience in VCs in all experience years except for "less than a year." The main reason behind this is the sudden decision made because of the COVID-19 pandemic wherein instructors are required to continue teaching their courses online.

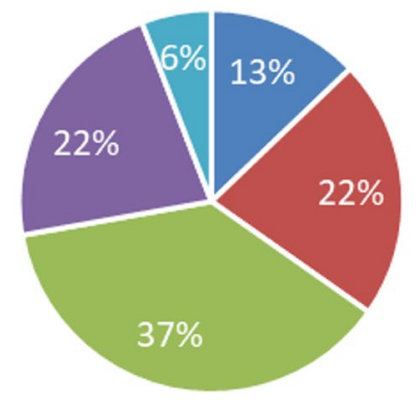

- Professor

- Associate professor

- Assistant Professor

- Lecturer

- Teaching Assistant

Fig. 3 Distribution of participants based on academic degree 


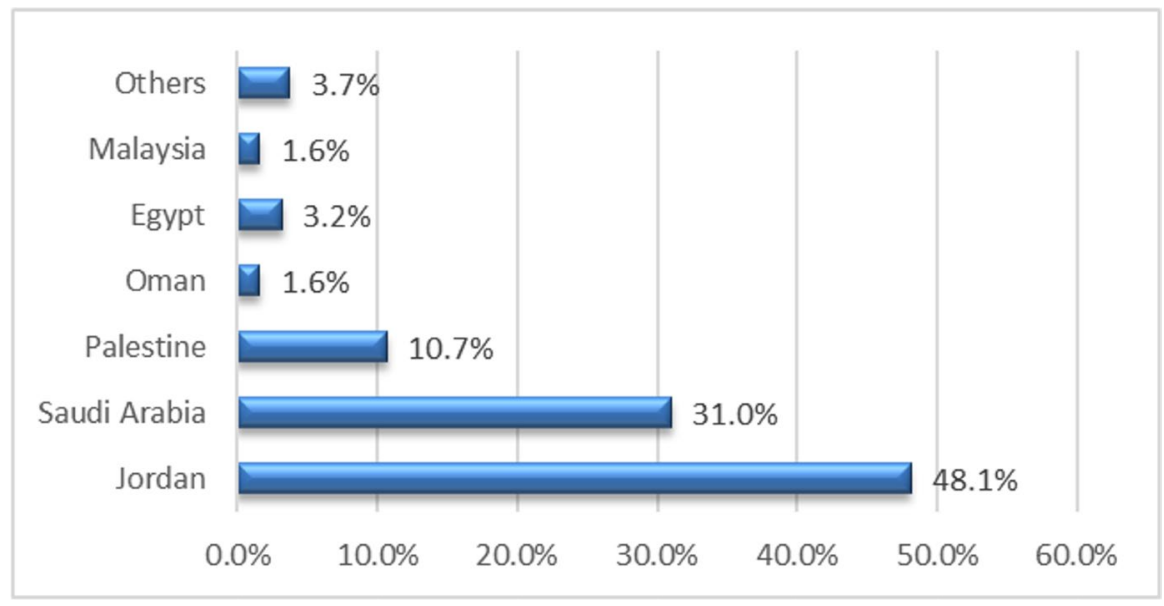

Fig. 4 Distribution of participants based on participants' country of teaching

Figure 7 illustrates whether or not the department/faculty has provided e-learning courses before the COVID-19 pandemic. The answers showed that almost two-thirds of the responses were positive at $67.9 \%$.

\subsection{Data analysis and discussion}

ANOVA test was applied to evaluate the instructors' perceptions of online teaching effectiveness compared to traditional teaching. Table 2 shows the ANOVA test results for instructors' perceptions of online teaching effectiveness compared to traditional teaching in terms of gender.

The quantitative analyses show that the average response ratings did not exceed the neutrality on any of the dimensional measures across all eight factors. This indicates that instructors are unable to decide whether online teaching is more effective

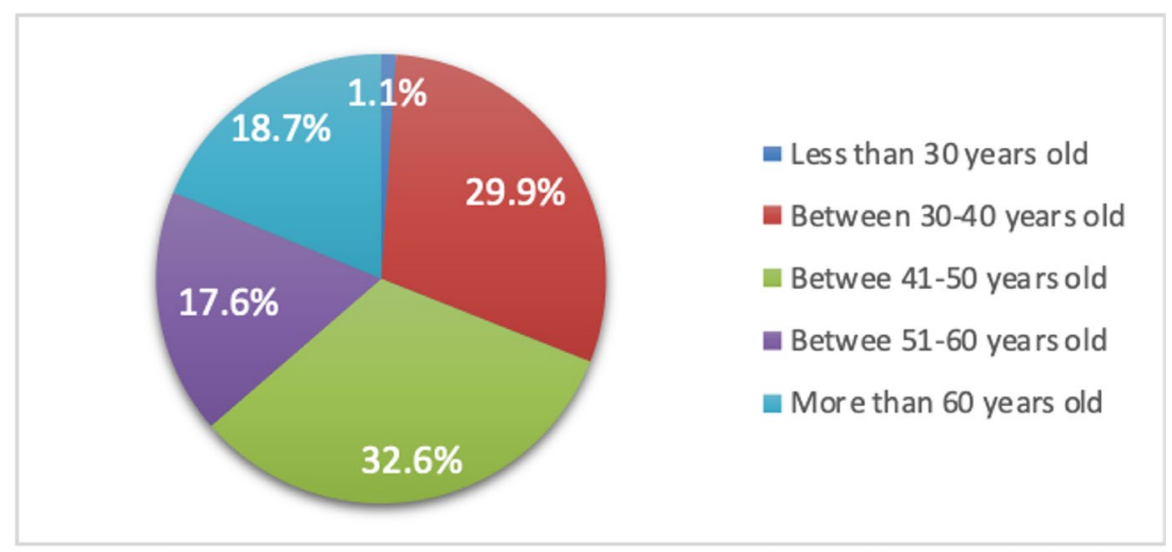

Fig. 5 Distribution of participants based on participants' ages 


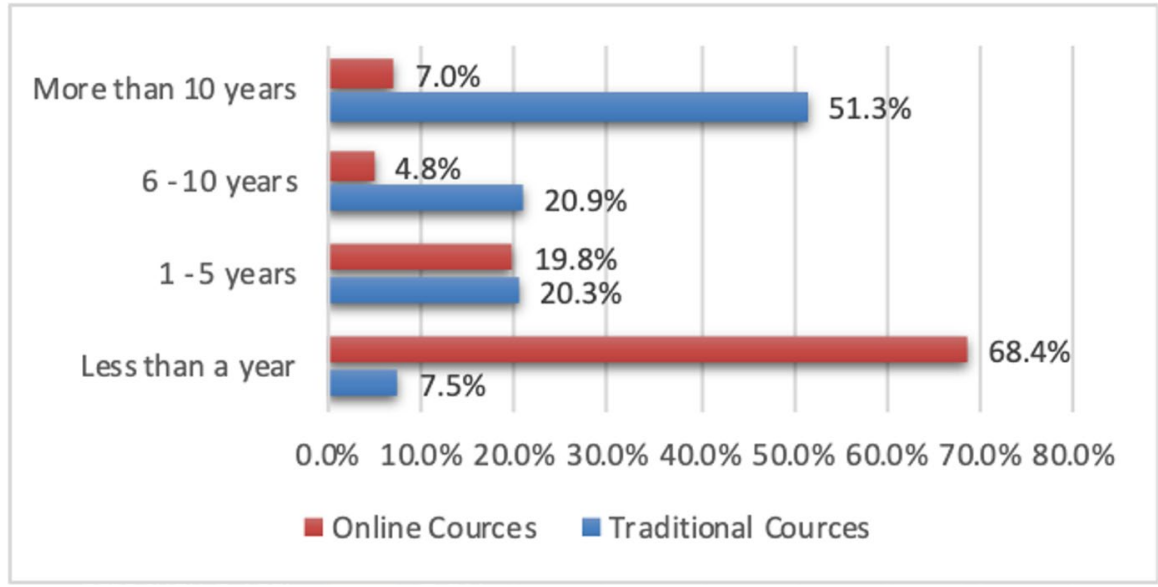

Fig. 6 Distribution of participants based on their teaching experiences in traditional and online classes

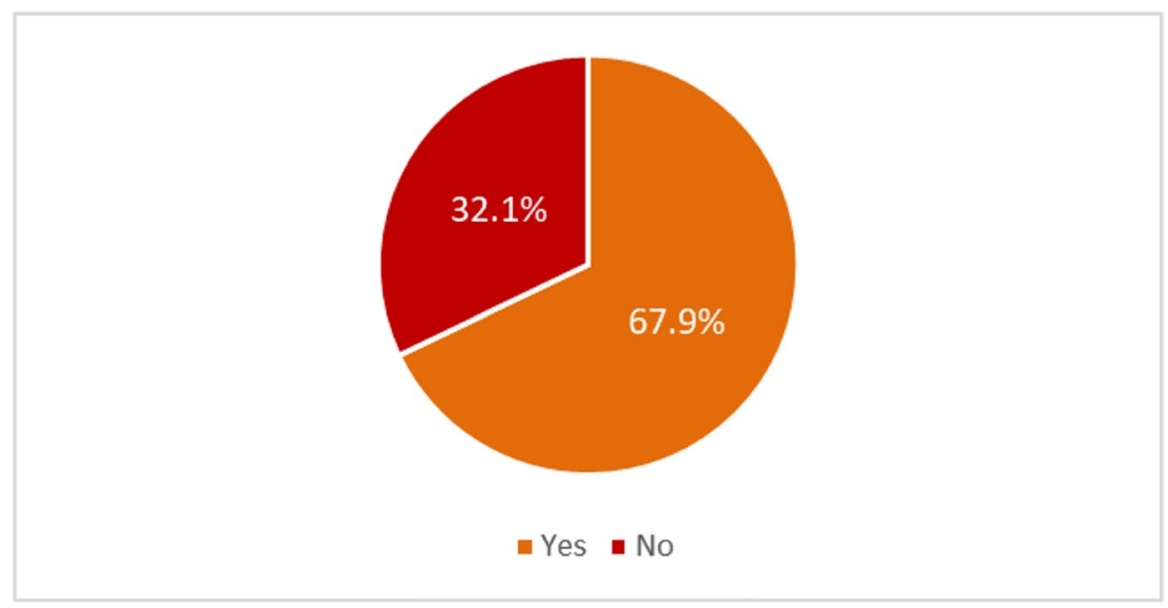

Fig. 7 Department/college provides e-learning courses before the COVID-19 pandemic (yes, no)

Table 2 ANOVA test results for dimension scales based on gender

\begin{tabular}{llllllc}
\hline Dimension Scales & Gender & $\mathrm{N}$ & Mean & Std & F_value & P_value \\
\hline Distance education effectiveness & Male & 127 & 2.55 & 0.79 & 0.003 & 0.95 \\
& Female & 60 & 2.56 & 0.75 & & \\
Distance education vs. traditional education & Male & 127 & 2.76 & 0.78 & 0.36 & 0.55 \\
& Female & 60 & 2.84 & 0.78 & & \\
Educator status & Male & 127 & 3.29 & 0.73 & 0.76 & 0.38 \\
& Female & 60 & 3.39 & 0.62 & & \\
\hline
\end{tabular}


Table 3 ANOVA test results for dimension scales based on academic major

\begin{tabular}{|c|c|c|c|c|c|c|}
\hline Dimension Scales & Major & $\mathrm{N}$ & Mean & Std & F_value & P_value \\
\hline \multirow[t]{7}{*}{ Distance education effectiveness } & Social and Human Sciences & 37 & 2.47 & 0.81 & \multirow[t]{7}{*}{0.62} & \multirow[t]{7}{*}{0.71} \\
\hline & Computer science and IT & 49 & 2.56 & 0.69 & & \\
\hline & Medical Sciences/Health & 47 & 2.48 & 0.78 & & \\
\hline & Applied Sciences & 29 & 2.59 & 0.90 & & \\
\hline & Engineering Sciences & 10 & 2.80 & 0.62 & & \\
\hline & Islamic Sciences & 4 & 2.82 & 1.54 & & \\
\hline & Others & 11 & 2.83 & 0.53 & & \\
\hline \multirow{7}{*}{$\begin{array}{l}\text { Distance education vs. traditional } \\
\text { education }\end{array}$} & Social and Human Sciences & 37 & 2.72 & 0.85 & \multirow[t]{7}{*}{0.48} & \multirow[t]{7}{*}{0.83} \\
\hline & Computer science and IT & 49 & 2.86 & 0.66 & & \\
\hline & Medical Sciences/Health & 47 & 2.71 & 0.84 & & \\
\hline & Applied Sciences & 29 & 2.76 & 0.78 & & \\
\hline & Engineering Sciences & 10 & 2.80 & 0.75 & & \\
\hline & Islamic Sciences & 4 & 3.06 & 1.30 & & \\
\hline & Others & 11 & 3.05 & 0.79 & & \\
\hline \multirow[t]{7}{*}{ Educator status } & Social and Human Sciences & 37 & 3.43 & 0.79 & \multirow[t]{7}{*}{1.09} & \multirow[t]{7}{*}{0.37} \\
\hline & Computer science and IT & 49 & 3.27 & 0.75 & & \\
\hline & Medical Sciences/Health & 47 & 3.29 & 0.72 & & \\
\hline & Applied Sciences & 29 & 3.25 & 0.60 & & \\
\hline & Engineering Sciences & 10 & 3.23 & 0.27 & & \\
\hline & Islamic Sciences & 4 & 4.08 & 0.75 & & \\
\hline & Others & 11 & 3.41 & 0.57 & & \\
\hline
\end{tabular}

than traditional teaching. This uncertainty comes as a result of instructors' experience in online teaching where $71.7 \%$ of participants have experience of less than a year, indicating that they start online teaching because of the COVID-19 pandemic taking into consideration that the survey was conducted in June 2020.

As shown in Table 2, the $\mathrm{P}$ value in all dimension scales is greater than 0.05 , indicating that no significant differences exist in instructors' perceptions in terms of gender meaning that instructors' perceptions of online teaching effectiveness-as compared to traditional teaching - do not contrast by instructors' gender, which supports our hypothesis $\left(h_{1}\right)$ and in contrast to the results observed by Seok et al. (2010) who showed that female instructors have statistically significant higher perceptions than males regarding the effectiveness of the online course.

Moreover, the mean results in every dimension scale show that both gender responses are closer to neutral than disagree on distance education effectiveness and distance education vs. traditional education dimension scales, and closer to neutral than agreement for educator status dimension scale. This indicates that instructors are unable to decide whether online teaching is more effective than traditional teaching or not. In addition, instructors' perceptions of variable 17 from the questionnaire show that instructors of both genders state that their efforts are well recognized and appreciated by the department /college /university. 
Table 4 ANOVA test results for dimension scales based on age

\begin{tabular}{lllllll}
\hline Dimension Scales & Age & N & Mean & Std & F_value & P_value \\
\hline Distance education effectiveness & Less than 30 & 2 & 3.21 & 1.31 & 1.05 & 0.38 \\
& $30-40$ & 56 & 2.52 & 0.71 & & \\
Distance education vs. traditional education & $41-50$ & 61 & 2.59 & 0.80 & & \\
& $51-60$ & 33 & 2.39 & 0.64 & & \\
& More than 60 & 35 & 2.69 & 0.94 & & \\
& $30-40$ & 56 & 2.71 & 0.74 & & \\
& $41-50$ & 61 & 2.90 & 0.74 & & \\
Educator status & $51-60$ & 33 & 2.64 & 0.75 & & \\
& More than 60 & 35 & 2.86 & 0.91 & & \\
& Less than 30 & 2 & 3.83 & 0.47 & 1.35 & 0.25 \\
& $30-40$ & 56 & 3.26 & 0.57 & & \\
& $41-50$ & 61 & 3.32 & 0.73 & & \\
& $51-60$ & 33 & 3.21 & 0.67 & & \\
& More than 60 & 35 & 3.53 & 0.85 & \\
\end{tabular}

Table 3 shows the ANOVA test results for instructors' perception of online teaching effectiveness compared to traditional teaching in terms of major. As shown in Table 3, the $\mathrm{P}$ value in all dimension scales is greater than 0.05 , indicating that no significant differences exist in instructors' perceptions in terms of major meaning that instructors' perceptions of online teaching effectiveness-compared with traditional teaching - do not contrast by instructors' major, which supports our hypothesis $\left(h_{1}\right)$. This is not in line with the findings observed by Alshangeeti et al. (2009), which found that a significant relationship exists between instructors' professional specialization and their perceptions regarding the attributes of online teaching.

The results show that the mean instructors' responses of the distance education effectiveness dimension scale are closer to neutral than disagree stating that, from instructors point of view, students' skills, knowledge, and interactions with instructors from various majors are not improved by transferring to distance education. Moreover, the mean results of the distance education vs. traditional education dimension scale show that responses are closer to neutral than disagree for instructors in social and human sciences, computer science and IT, medical sciences/health, applied sciences, and engineering sciences majors, whereas instructors in Islamic sciences major and other majors are closer to neutral than agree. This concludes that instructors in Islamic sciences major have slightly more positive opinions toward transferring to online teaching.

Finally, the mean results of the educator status dimension scale show that the responses are closer to neutral than agree except those in the Islamic sciences major who are closer to agree than strongly agree. Meaning that instructors in the Islamic sciences major receive more positive encouragements toward adapting distance education than other majors. 
Table 5 ANOVA test results for dimension scales based on country

\begin{tabular}{|c|c|c|c|c|c|c|}
\hline Dimension Scales & Country & $\mathrm{N}$ & Mean & Std & F_value & P_value \\
\hline \multirow[t]{7}{*}{ Distance education effectiveness } & Egypt & 6 & 2.31 & 0.31 & \multirow[t]{7}{*}{1.74} & \multirow[t]{7}{*}{0.12} \\
\hline & Jordan & 90 & 2.61 & 0.78 & & \\
\hline & Malaysia & 3 & 2.57 & 1.00 & & \\
\hline & Oman & 3 & 1.81 & 0.86 & & \\
\hline & Palestine & 20 & 2.84 & 0.66 & & \\
\hline & Saudi Arabia & 58 & 2.41 & 0.81 & & \\
\hline & Others & 7 & 2.96 & 0.75 & & \\
\hline \multirow[t]{7}{*}{ Distance education vs. traditional education } & Egypt & 6 & 2.67 & 0.30 & \multirow[t]{7}{*}{1.37} & \multirow[t]{7}{*}{0.23} \\
\hline & Jordan & 90 & 2.84 & 0.79 & & \\
\hline & Malaysia & 3 & 2.75 & 1.39 & & \\
\hline & Oman & 3 & 2.50 & 1.09 & & \\
\hline & Palestine & 20 & 3.01 & 0.69 & & \\
\hline & Saudi Arabia & 58 & 2.62 & 0.80 & & \\
\hline & Others & 7 & 3.29 & 0.53 & & \\
\hline \multirow[t]{7}{*}{ Educator status } & Egypt & 6 & 3.42 & 0.35 & \multirow[t]{7}{*}{1.81} & \multirow[t]{7}{*}{0.10} \\
\hline & Jordan & 90 & 3.36 & 0.72 & & \\
\hline & Malaysia & 3 & 3.06 & 0.63 & & \\
\hline & Oman & 3 & 2.61 & 0.92 & & \\
\hline & Palestine & 20 & 3.65 & 0.54 & & \\
\hline & Saudi Arabia & 58 & 3.19 & 0.73 & & \\
\hline & Others & 7 & 3.45 & 0.55 & & \\
\hline
\end{tabular}

Table 4 shows the ANOVA test results for instructors' perceptions of online teaching effectiveness compared to traditional teaching in terms of age.

As shown in Table 4, the $\mathrm{P}$ value in all dimension scales is greater than 0.05 indicating that no significant differences exist in instructors' perceptions in terms of age meaning that instructors' perceptions of online teaching effectiveness-compared with traditional teaching-do not contrast by instructors' age, which supports our hypothesis $\left(h_{1}\right)$, which agreed with the results obtained by Alshangeeti et al. (2009).

Furthermore, based on the mean results of the distance education effectiveness dimension scale, responses in all ages are closer to neutral than disagree except ages that less than 30 and ages from 51 to 60 , who are closer to neutral than agree and closer to disagree than neutral, respectively. This concludes that younger instructors perceive distance education more positively than elder instructors. Moreover, the mean results of the distance education vs. traditional dimension scale show that responses in all ages are closer to neutral than disagree except the ages that less than 30 , who are closer to neutral than agree, indicating that younger instructors find distance education promising and full of potentials. Finally, the mean results of the educator status dimension scale show that responses in all ages are closer to neutral than agree except the ages that less than 30 and greater than 60, who are closer to agree than neutral, indicating that most younger and most elder instructors 
Table 6 ANOVA test results for dimension scales based on academic degree

\begin{tabular}{lllllll}
\hline Dimension Scales & Degree & N & Mean & Std & F_value & P_value \\
\hline Distance education effectiveness & Professor & 24 & 2.38 & 0.68 & 2.75 & 0.03 \\
& Associate professor & 41 & 2.60 & 0.85 & & \\
& Assistant Professor & 70 & 2.40 & 0.70 & & \\
& Lecturer & 41 & 2.77 & 0.82 & & \\
Distance education vs. traditional education & Teaching Assistant & 11 & 2.99 & 0.84 & & \\
& Professor & 24 & 2.69 & 0.89 & 1.32 & 0.26 \\
& Associate professor & 41 & 2.87 & 0.72 & & \\
& Assistant Professor & 70 & 2.66 & 0.69 & & \\
& Lecturer & 41 & 2.92 & 0.89 & & \\
Educator status & Teaching Assistant & 11 & 3.09 & 0.87 & & \\
& Professor & 24 & 3.29 & 0.80 & 1.81 & 0.13 \\
& Associate professor & 41 & 3.18 & 0.69 & & \\
& Assistant Professor & 70 & 3.27 & 0.68 & & \\
& Lecturer & 41 & 3.57 & 0.73 & & \\
& Teaching Assistant & 11 & 3.38 & 0.44 & \\
\hline
\end{tabular}

find distance education prestigious and obtain more positive encouragements toward moving to distance education than others.

Table 5 shows the ANOVA test results for instructors' perceptions of online teaching effectiveness compared to traditional teaching in terms of country of teaching.

As shown in Table 5, $\mathrm{P}$ values are greater than 0.05 for all dimension scales, indicating that no significant differences exist in instructors' perceptions in terms of country of teaching meaning that instructors' perceptions of online teaching effectiveness - compared with traditional teaching — do not contrast by instructors' country of teaching, which supports our hypothesis $\left(h_{1}\right)$. These results are inconsistent with the results of Alenezi (2012) who stated that lecturer's perceptions of e-learning were influenced by their nationality.

Furthermore, based on to the mean results of the distance education effectiveness dimension scale, responses from all countries are closer to neutral than disagree except responses from Egypt, Saudi Arabia, and Oman, which are closer to disagree than neutral. Meaning that instructors from Egypt, Saudi Arabia, and Oman favor conventional in-class teaching over online teaching. Moreover, the mean results of the distance to the traditional dimension scale show that responses from all countries are closer to neutral than disagree except responses from Palestine and others, which are closer to neutral than agree. This indicates that Palestinian instructors have slightly more positive opinions toward distance education. Finally, the mean results of educator status dimension scale show that responses from all countries are close to neutral, except those from Palestine, which are close to agree, indicating that Palestinian instructors obtain more encouragements toward moving to distance education. 
Table 7 ANOVA test results for dimension scales based on supporting VC

\begin{tabular}{lllllll}
\hline Dimension Scales & Supporting VC & N & Mean & Std & F_value & P_value \\
\hline Distance education effectiveness & Yes & 127 & 2.63 & 0.81 & 3.615 & 0.059 \\
& No & 60 & 2.40 & 0.69 & & \\
Distance education vs. traditional education & Yes & 127 & 2.83 & 0.78 & 0.714 & 0.399 \\
& No & 60 & 2.72 & 0.79 & & \\
Educator status & Yes & 127 & 3.41 & 0.69 & 6.051 & 0.015 \\
& No & 60 & 3.14 & 0.71 & & \\
\hline
\end{tabular}

Table 6 shows the ANOVA test results for instructors' perceptions of online teaching effectiveness compared to traditional teaching in terms of degree/rank.

As shown in Table 6, a significant difference is detected in instructors' perceptions on the basis of academic degree for distance education effectiveness dimension scale, which contradict with the study's hypothesis $\left(h_{1}\right)$. Meanwhile, the study's hypothesis $\left(h_{1}\right)$ holds in the other two scales. This agreed with the results obtained by Alshangeeti et al. (2009), which reported that no evidence exists for any relationship between educational level and perceptions of online teaching attributes.

Moreover, based on to the mean results of the distance education effectiveness dimension scale, instructors' opinions of associate professors, lecturers, and teaching assistants are closer to neutral than disagree, whereas the responses of professors and assistant professors are closer to disagree than neutral. These values indicate that professors and assistant professors favor conventional in-class teaching over online teaching. Furthermore, the mean results of the distance education vs. traditional dimension scale show that responses are closer to neutral than disagree except teaching assistants, who are closer to neutral than agree, indicating that lecturers have slightly more positive opinions toward distance education. Finally, the mean results of the educator status dimension scale show that the responses from all academic degrees are closer to neutral than agree except those from lecturers, which are closer to agree than neutral, indicating that lecturers are more motivated than other instructors.

Table 7 shows the ANOVA test results for instructors' perceptions of online teaching effectiveness compared to traditional teaching in terms of supporting VCs.

As shown in Table 7, a significant difference is detected in instructors' perceptions on the basis of whether or not the departments used to support VCs for educator status dimension scale, which contradict with the study's hypothesis (h1). Meanwhile, the study's hypothesis (h1) holds in the other two scales.

Furthermore, based on the mean results of the distance education effectiveness dimension scale, the responses of participants in departments that support VCs are closer to neutral than disagree, whereas the responses of participants in departments that do not support VCs are closer to disagree than neutral. The responses indicate that instructors working in departments that suffer from lack of experience in VCs find traditional in-class teaching better than distance education. Moreover, the mean 
Table 8 ANOVA test results for dimension scales based on traditional experience

\begin{tabular}{|c|c|c|c|c|c|c|}
\hline Dimension Scales & Traditional experience & $\mathrm{N}$ & Mean & Std & F_value & P_value \\
\hline \multirow[t]{4}{*}{ Distance education effectiveness } & Less than a year & 14 & 3.00 & 0.80 & \multirow[t]{4}{*}{2.03} & \multirow[t]{4}{*}{0.11} \\
\hline & $1-5$ & 38 & 2.58 & 0.83 & & \\
\hline & $6-10$ & 39 & 2.61 & 0.85 & & \\
\hline & More than 10 years & 96 & 2.47 & 0.72 & & \\
\hline \multirow{4}{*}{$\begin{array}{l}\text { Distance education vs. traditional educa- } \\
\text { tion }\end{array}$} & Less than a year & 14 & 3.20 & 0.79 & \multirow[t]{4}{*}{2.29} & \multirow[t]{4}{*}{0.08} \\
\hline & $1-5$ & 38 & 2.74 & 0.72 & & \\
\hline & $6-10$ & 39 & 2.94 & 0.76 & & \\
\hline & More than 10 years & 96 & 2.69 & 0.80 & & \\
\hline \multirow[t]{4}{*}{ Educator status } & Less than a year & 14 & 3.81 & 0.62 & \multirow[t]{4}{*}{3.32} & \multirow[t]{4}{*}{0.02} \\
\hline & $1-5$ & 38 & 3.38 & 0.76 & & \\
\hline & $6-10$ & 39 & 3.14 & 0.62 & & \\
\hline & More than 10 years & 96 & 3.31 & 0.70 & & \\
\hline
\end{tabular}

results of the distance education vs. traditional dimension scale show that participants' responses are closer to neutral than disagree, indicating that participants from both are unable to decide which teaching mechanism is better. Meanwhile, the mean results of the educator status dimension scale show that participants' responses are closer to neutral than agree, indicating that the instructors who work in departments used to support VCs think positively and enthusiastically toward online teaching.

Table 8 shows the ANOVA test results for instructors' perceptions of online teaching effectiveness compared to traditional teaching in terms of traditional teaching experience.

As shown in Table 8, a significant difference is detected in instructors' perceptions based on traditional teaching experience for educator status dimension scale, which contradicts with the study's hypothesis $\left(h_{1}\right)$. Meanwhile, the study's hypothesis $\left(h_{1}\right)$ holds in the other two scales, which agreed with the results obtained by Alshangeeti et al. (2009).

Furthermore, regarding the mean results of the distance education effectiveness dimension scale, all participants' responses are closer to neutral than disagree, except those with experience greater than 10 years, who are closer to disagree than neutral. This concludes that instructors with high experience in traditional teaching favor traditional teaching over online teaching. In addition, the mean results of the distance vs. traditional teaching dimension scale show that participants with traditional teaching experience of more than a year (92\% of participants) are closer to neutral than disagree, whereas participants who have experience of less than a year ( $8 \%$ of participants) are closer to neutral than agree. Even though the responses are pointing toward undecided, instructors with less experience slightly tend to move from traditional teaching toward distance education. Finally, the mean results of the educator status dimension scale show that participants with traditional teaching experience of more than a year are closer to neutral than agree, whereas participants who have experience of less than a year are closer to agree than neutral, indicating that instructors with less experience 
Table 9 ANOVA test results for dimension scales based on virtual experience

\begin{tabular}{|c|c|c|c|c|c|c|}
\hline Dimension Scales & Virtual experience & $\mathrm{N}$ & Mean & Std & F_value & P_value \\
\hline \multirow[t]{4}{*}{ Distance education effectiveness } & Less than a year & 128 & 2.54 & 0.77 & \multirow[t]{4}{*}{0.75} & \multirow[t]{4}{*}{0.53} \\
\hline & $1-5$ & 37 & 2.64 & 0.76 & & \\
\hline & $6-10$ & 9 & 2.81 & 0.85 & & \\
\hline & More than 10 years & 13 & 2.36 & 0.96 & & \\
\hline \multirow[t]{4}{*}{ Distance education vs. traditional education } & Less than a year & 128 & 2.74 & 0.77 & \multirow[t]{4}{*}{1.23} & \multirow[t]{4}{*}{0.30} \\
\hline & $1-5$ & 37 & 2.85 & 0.85 & & \\
\hline & $6-10$ & 9 & 3.22 & 0.65 & & \\
\hline & More than 10 years & 13 & 2.87 & 0.79 & & \\
\hline \multirow[t]{4}{*}{ Educator status } & Less than a year & 128 & 3.30 & 0.67 & \multirow[t]{4}{*}{0.86} & \multirow[t]{4}{*}{0.46} \\
\hline & $1-5$ & 37 & 3.39 & 0.71 & & \\
\hline & $6-10$ & 9 & 3.63 & 0.58 & & \\
\hline & More than 10 years & 13 & 3.21 & 1.04 & & \\
\hline
\end{tabular}

find distance education prestigious and obtain more encouragements from the department toward moving to online teaching than others.

Table 9 shows the ANOVA test results for instructors' perceptions of online teaching effectiveness compared to traditional teaching in terms of virtual teaching experience.

As shown in Table 9, $\mathrm{P}$ values are greater than 0.05 in all dimension scales, indicating that no significant differences exist in instructors' perceptions in terms of virtual teaching experience meaning that instructors' perceptions of online teaching effectiveness - compared with traditional teaching — do not contrast by instructors' virtual teaching experience, which supports our hypothesis $\left(h_{1}\right)$ and contrasted with the results obtained by Ulmer et al. (2007).

Furthermore, based on the mean results of the distance education effectiveness dimension scale, responses from all participants are closer to neutral than disagree, except those with experience greater than 10 years, who are closer to disagree than neutral. Furthermore, instructors with more experience in VCs observe that students favor traditional in-class teaching over online teaching. Moreover, the mean results of the distance education vs. traditional education dimension scale show that all participants are closer to neutral than disagree, except those with experience of 6-10 years, who are closer to neutral than agree. Finally, the mean results of the educator status dimension scale show that the responses from all participants are closer to neutral than agree except those from participants with experiences of 6-10 years, which are closer to agree than neutral, indicating that instructors with more experience in VCs find distance education prestigious and obtain more positive encouragements toward moving to distance education than others.

Table 10 summarizes the $P_{-}$value results for the five-dimension scales in all factors. In total, $12.5 \%$ of the $\mathrm{P}$ values' results show significant differences for instructors' perceptions of online teaching effectiveness compared with traditional in-class teaching (highlighted in bold), whereas $87.5 \%$ of $\mathrm{P}$ values' results do not show any significant differences. 
Table 10 Summary table of $\mathrm{P}_{-}$Value results for the 5D scales in all factors

\begin{tabular}{llll}
\hline $\begin{array}{l}\text { Dimension } \\
\text { Scales Factors }\end{array}$ & $\begin{array}{l}\text { Distance education } \\
\text { effectiveness }\end{array}$ & $\begin{array}{l}\text { Distance education vs. tradi- } \\
\text { tional education }\end{array}$ & Educator status \\
\hline Gender & 0.95 & 0.55 & 0.38 \\
Major & 0.71 & 0.83 & 0.37 \\
Age & 0.38 & 0.46 & 0.25 \\
Country & 0.12 & 0.23 & 0.10 \\
Academic degree & $\mathbf{0 . 0 3}$ & 0.26 & 0.13 \\
Supporting VC & 0.059 & 0.399 & $\mathbf{0 . 0 1 5}$ \\
Traditional experience & 0.11 & 0.08 & $\mathbf{0 . 0 2}$ \\
Virtual experience & 0.53 & 0.30 & 0.46 \\
\hline
\end{tabular}

\section{Conclusion and future works}

This study explores the perceptions of instructors on distance learning during the COVID-19 pandemic. 3D scales, namely, distance education effectiveness, distance education compared to traditional education, and educator status, are applied to analyze data on the perceptions of 187 instructors from various universities and academic degrees. The study explored the effects of eight factors on the instructors' perspectives, including major specifications, academic degree, country of teaching, age, teaching experience in traditional classes, teaching experience in VCs, and whether or not the department/faculty provided e-learning courses before the COVID-19 pandemic.

However, the findings of studying the teaching effectiveness of instructors' perceptions using traditional and virtual online teaching systems illustrate that no significant differences exist (87.5\% of $\mathrm{P}$ values' results for all factors) in all dimension scales in terms of gender, major specification, age, country of teaching, and virtual experience. In comparison, significant differences $(12.5 \%$ of $\mathrm{P}$ values' results for all factors) are found in the dimension scale of distance education effectiveness in terms of academic degree, the educator status of supporting VCs, and traditional experience. Moreover, the quantitative analyses show that the average response ratings did not exceed neutrality on any of the dimensional measures across all factors studied. Moreover, the dimension scale of educator status achieves the highest average score in all studied factors.

On the basis of the study, we find that: younger and less experience lecturers (less than a year) perceive distance education more positively and they are more motivated to transfer from traditional teaching to online teaching than other lecturers. Moreover, they feel that they receive more positive encouragements toward adapting distance education from their institutions than other lecturers. In addition, most of the participated lecturers feel that they are not motivated by their institutions to shift from traditional teaching to online teaching. Furthermore, lecturers and students lack awareness about the importance and advantages of distance education over traditional teaching. 
On the basis of the findings, we recommend that: departments should strive toward encouraging and motivating teaching staff to transfer from traditional teaching to online teaching. Moreover, the departments must increase instructors' and students' awareness of online teaching importance and develop and improve their skills of how to utilize distance education.

Based on lecturer's responses, the unexpected shift from traditional teaching to online teaching during COVID19 pandemic negatively affects teaching and learning effectiveness. This depletion of teaching and learning effectiveness are caused by several factors including; lack of lecturer's experience in online teaching and lack of appropriate orientations and guidance for lecturers and students of online teaching importance, capabilities, and proper utilization.

Although the acceptance rate of online teaching is increasing especially among young and less experience lecturers, based on lecturer's responses, the majority of lecturers tend to resist transfer from traditional teaching toward online teaching. Thus, it can be concluded that institutions that used to apply traditional teaching before the COVID-19 pandemic will return to normal traditional teaching after the pandemic.

Future studies should focus on exploring the effects of other factors, which influence the lecturers' perceptions, using data mining tools that can assist researchers from diverse interests and expertise in their works.

\section{Nomenclatures}

P_value: Refers to a numeric quantity computed for sample statistics within the context of hypothesis testing; $F_{-}$value: Refers to a value on the F distribution; Std.: Refers to the standard deviation

\section{Abbreviations}

COVID-19: Coronavirus disease 2019; VCs: Virtual Classes; DTPB: Decomposed Theory of Planned Behavior; IT: Information Technology; ANOVA: Analysis of Variance

\section{References}

Affouneh, S., \& Raba, A. A. (2018). Trends of the recorded lectures at An-Najah National University from the staff faculty perspectives. Journal of Educational Research and Reviews, 6(5), 71-79.

Alenezi, A. (2012). Faculty members' perception of e-learning in higher education in the Kingdom of Saudi Arabia(KSA), Doctoral dissertation, Texas Tech University

Alshangeeti, A., Alsaghier, H., \& Nguyen, A. (2009). Faculty perceptions of attributes affecting the diffusion of online learning in Saudi Arabia: A quantitative study. In Proceedings of the international conference on e-learning, 10-24.

Alshalawi, A. S. (2019). An Investigation of the Adoption of Social Media Applications by Faculty Members at a Prominent University in the Kingdom of Saudi Arabia, Doctoral dissertation, Florida Institute of Technology University. 
Allen, M., Bourhis, J., Burrell, N., \& Mabry, E. (2002). Comparing student satisfaction with distance education to traditional classrooms in higher education: A meta-analysis. The American Journal of Distance Education, 16(2), 83-97.

Al-Shboul, M. (2013). The level of E-Learning integration at the University of Jordan: Challenges and Opportunities. International Education Studies, 6(4), 93-113.

Arias, J. J., Swinton, J., \& Anderson, K. (2018). Online vs. face-to-face: A comparison of student outcomes with random assignment. E-Journal of Business Education and Scholarship of Teaching, 12(2), 1-23.

Behzadi, Z., \& Ghaffari, A. (2011). Characteristics of online education and traditional education. Life Science Journal, 8(3), 54-58.

Bernard, R. M., Abrami, P. C., Lou, Y., Borokhovski, E., Wade, A., Wozney, L., \& Huang, B. (2004). How does distance education compare with classroom instruction? A meta-analysis of the empirical literature. Review of Educational Research, 74(3), 379-439.

Blackboard (2020). Blackboard learning system, https://blackboard.com. last access Jun 2020.

Canvas (2020). Canvas Learning Management Platform, https://www.canvas.net/, last accessed Jun 2020.

Frazer, C., Sullivan, D. H., Weatherspoon, D., \& Hussey, L. (2017). Faculty perceptions of online teaching effectiveness and indicators of quality. Nursing Research and Practice, 2017, 1-6.

Gowda R. S., \& Suma V. (2017). "A comparative analysis of traditional education system vs. e-Learning," International Conference on Innovative Mechanisms for Industry Applications (ICIMIA), Bangalore, 2017, pp. 567-571. https://doi.org/10.1109/ICIMIA.2017.7975524

Gürer, M., Tekinarslan, E., \& Yavuzalp, N. (2016). Opinions of instructors who give lectures online about distance education. Turkish Online Journal of Qualitative Inquiry, 7(1), 47-78.

Hannay, M., \& Newvine, T. (2006). Perceptions of distance learning: A comparison of online and traditional learning. Journal of Online Learning and Teaching, 2(1), 1-11.

Hsiao, Y.-C. (2021). "Impacts of course type and student gender on distance learning performance: A case study in Taiwan." Education and Information Technologies, 1-16.

Hurlbut, A. R. (2018). Online vs. traditional learning in teacher education: a comparison of student progress. American Journal of Distance Education, 32(4), 248-266.

Khatri B., Chouskey P., \& Singh M. (2013). Comparative Analysis Study of E-learning and Traditional Learning in Technical Institution, 2013 International Conference on Communication Systems and Network Technologies, pp. 770-773. https://doi.org/10.1109/CSNT.2013.165

Lazou, C., \&Tsinakos, A. (2019). Online Versus Traditional Learning Environments: What to Inspect, Respect, and Expect. Athabasca University.

Liu, C.-H. (2010). The comparison of learning effectiveness between traditional face-to-face learning and e-learning among goal-oriented users, 6th International Conference on Digital Content, Multimedia Technology and its Applications, pp. 255-260.

McKenzie, W. (2019). Experiences of graduate-level Faculty regarding interaction in online courses. $\mathrm{PhD}$. Thesis, Sam Houston State University, Huntsville, Texas.

Moodle (2020). Moodle learning system, https://moodle.org/. last accessed Jun 2020.

Narayan, N., \& Singh, S. K. (2020). Online learners' experiences and views towards online courses: A case study of the University of the South Pacific. Directions: Journal of Educational Studies, 34(1), 29-41.

Nelson, J. (2003). Integration of course management system communication tools in instruction. Unpublished Dissertation, University of Tennessee, Knoxville, TN.

Okoye, K., Rodriguez-Tort, J. A., Escamilla, J., \& Hosseini, S. (2021). Technology-mediated teaching and learning process: A conceptual study of educators' response amidst the Covid-19 pandemic. Education and Information Technologies, 1-33.

Plante, K., \& Asselin, M. E. (2014). Best practices for creating social presence and caring behaviors online. Nursing Education Perspectives, 35(4), 219-223.

Ralph, R., Lew, J., Zeng, T., Francis, M., Xue, B., Roux, M., \& Kelvin, D. J. (2020). 2019-nCoV (Wuhan virus), a novel Coronavirus: Human-to-human transmission, travel-related cases, and vaccine readiness. The Journal of Infection in Developing Countries, 14(01), 3-17.

Richardson J. C., Besser E., Koehler A., Lim J., \& Strait M. (2016), "Instructors' perceptions of instructor presence in online learning environments, The International Review of Research in Open and Distributed Learning, vol. 17, no. 4

Saleh, A., \& Mrayan, S. A. (2016). Faculty Perceptions of Online Teacher Education Programs in Jordan: A Case Study. Asian Journal of Education and e-Learning (ISSN: 2321-2454), 4(06). 
Samuel, A. (2016). Faculty Perceptions and Experiences of "presence" in the Online Learning Environment. PhD. Dissertations, University of Wisconsin-Milwaukee.

Seok, S., DaCosta, B., Kinsell, C., \& Tung, C. K. (2010). Comparison of instructors' and students' perceptions of the effectiveness of online courses. Quarterly Review of Distance Education, 11(1), 25.

Shachar, M., \& Neumann, Y. (2003). Differences between traditional and distance education academic performances: A meta-analytic approach. The International Review of Research in Open and Distributed Learning, 4(2).

Shambour, M. K., \& Gutub, A. (2021). Progress of IoT Research Technologies and Applications Serving Hajj and Umrah. Arabian Journal for Science and Engineering, 1-21.

Shreaves, D. (2019). Faculty Perceptions of Online Teaching at a Mid-Sized Liberal Arts University in the Pacific Northwest: A Mixed Methods Study. PhD.Dissertations, Boise State University.

Sibirskaya, E., Popkova, E., Oveshnikova, L., \& Tarasova, I. (2019). Remote education vs traditional education based on effectiveness at the micro level and its connection to the level of development of macro-economic systems. International Journal of Educational Management, 11-22.

Sitzmann, T., Kraiger, K., Stewart, D., \& Wisher, R. (2006). The comparative effectiveness of web-based and classroom instruction: A meta-analysis. Personnel Psychology, 59(3), 623-664.

Trakru, M., \& Jha, T. K. (2019). E-learning effectiveness in higher education. International Research Journal of Engineering and Technology (IRJET), 6(5), 96-101.

Uhlig, G. E. (2002). The present and future of distance learning. Education, 122(4), 670-673.

Ulmer, L. W., Watson, L. W., \& Derby, D. (2007). Perceptions of higher education faculty members on the value of distance education. Quarterly Review of Distance Education, 8(1).

Webex (2020). Cisco Webex, https://webex.com/. last accessed Jun 2020.

Wingo, N. P., Ivankova, N. V., \& Moss, J. A. (2017). Faculty perceptions about teaching online: Exploring the literature using the technology acceptance model as an organizing framework. Online Learning, 21(1), 15-35.

Willett, J., Brown, C., \& Danzy-Bussell, L. A. (2019). An exploratory study: Faculty perceptions of online learning in undergraduate sport management programs. Journal of Hospitality, Leisure, Sport \& Tourism Education, 25, 100206.

Yerby, J., \& Floyd, K. (2013). An investigation of traditional education vs. Fully-online education in information technology. Association for Information Systems AIS Electronic Library (AISeL), 213-2018.

Publisher's note Springer Nature remains neutral with regard to jurisdictional claims in published maps and institutional affiliations.

\section{Authors and Affiliations}

\section{Mohd Khaled Yousef Shambour ${ }^{1}$. Muhannad A. Abu-Hashem ${ }^{2}$}

Mohd Khaled Yousef Shambour

myshambour@uqu.edu.sa

Muhannad A. Abu-Hashem

mabohasm@kau.edu.sa

1 Department of Information and Scientific Services, the Custodian of the Two Holy Mosques Institute for Hajj and Umrah Research, Umm Al-Qura University, Makkah, Saudi Arabia

2 Department of Geomatics, Architecture and Planning Faculty, King Abdulaziz University, Jeddah, Saudi Arabia 